Investigations

\title{
Digestion and Metabolism Indices of Sheep When Using Activated Charcoal Supplement
}

\author{
${ }^{1}$ Nadezhda Vladimirovna Bogolyubova, ${ }^{2}$ Vasily Pavlovich Korotky, ${ }^{3}$ Alexander Sergeyevich Zenkin, \\ ${ }^{4}$ Viktor Anatolyevich Ryzhov and ${ }^{5}$ Nikolai Petrovich Buryakov \\ ${ }^{1}$ Federal State Budgetary Scientific Institution, Ernst All-Russia Research Institute for Animal Husbandry, \\ 142132, Russia, Moscow Region, Podolsk, Dubrovitsy, 60, Russia \\ ${ }^{2}$ Science and Technology Center "Khiminvest" Ltd., 603001, Russia, \\ Nizhny Novgorod, Nizhne-Volzhskayanaberezhnaya, 6/1, Russia \\ ${ }^{3}$ Mordovia Ogarev State University, 430005, Russia, Republic of Mordovia, \\ Saransk, Bolshevistskaya Str., 68, Russia \\ ${ }^{4}$ Science and Technology Center "Khiminvest" Ltd., 603001, Russia, \\ Nizhny Novgorod, Nizhne-Volzhskayanaberezhnaya, 6/1, Russia \\ ${ }^{5}$ Russian State Agrarian University - Moscow Timiryazev Agricultural Academy, \\ 127550, Russia, Moscow, Timiryazevskaya Str., 49, Russia
}

Article history

Received: 12-05-2017

Revised: 07-06-2017

Accepted: 15-06-2017

Corresponding Author:

Alexander Sergeyevich Zenkin

Mordovia Ogarev State

University, 430005, Russia,

Republic of Mordovia,

Saransk, Bolshevistskaya Str.,

68, Russia

Email: zenkin50@mail.ru

\begin{abstract}
The effect of activated charcoal as a feed additive was assessed in the experiment with Romanov sheep and Romanov sheep breed with argali. Charcoal sorbent is the original preparation produced in "Khiminvest" Science and Technology Center. Activated charcoal supplement was added to the basic diet of experimental animals in an amount of $1 \mathrm{~g}$ per $10 \mathrm{~kg}$ of live weight. The preparation showed positive effect on the palatability of the feed and ruminal digestion processes, as well as contributed to an increase in dry matter concentration of microorganisms and amylase activity. Experimental sheep showed an increase of digestibility of dry matter, dry protein, crude fat, crude fiber, bio-effecting agents, as well as increased nitrogen utilization coefficient. Use of the preparation provided increase in daily weight gains.
\end{abstract}

Keywords: Sheep, Activated Charcoal as a Feed Additive, Digestion, Digestibility, Metabolism, Weight Gain

\section{Introduction}

Effective way of enhancing the adaptive capacity of the animal organism is the optimization and stimulation of physiological functions through the use of bioeffecting agents as bio-correctors of the various digestive and metabolic processes (Ernst and Zinovieva, 2008). The unbalanced diets and the increased content of concentrates cause a violation of the digestive processes, reducing digestive and absorbing capacity of the gastrointestinal tract (Aliyev 1997; 2001). However in practice, modern animal production uses diets unbalanced in terms of key nutrients, feeding animals with poor quality feed contaminated with substances of different origin, bearing in their composition different xenobiotics such as pesticides, nitrates, dioxins and mycotoxins (Romanov et al., 2015). In this regard, the development of effective veterinary preparations (including feed additives) to correct pathological processes caused by different xenobiotics is fairly relevant issue (Tremasova, 2014). The present work deals with the development of new biocorrectors for animal production.

\section{Methodology}

The present research is based on the methodology dealing with comprehensive study of nutrition processes (Sinechshokov and Sheremet, 1953). It involves simultaneous conduction of physiological, biochemical and microbiological studies on the background of digestibility tests. The experiment was carried out at the physiological farm of the All-Russian Scientific Research Institute of Animal Breeding named after Academician L.K. Ernst using multi-period group method in different genotype sheep, namely Romanov breed (ROM) and hybrid of Romanov breed and argali (ROMARG). The experiment involved 6 animals per group, having live weight of $30 \mathrm{~kg}$. The Main Diet (MD) 
was supplemented with $1.2 \mathrm{~kg}$ of cock's-foot hay and 0.4 $\mathrm{kg}$ of complete feed. The animals of the test groups were fed the diet which included Activated Charcoal Supplement (ACS) in an amount of $1 \mathrm{~g}$ per $10 \mathrm{~kg}$ of live weight. Animals were fed 2 times a day every $12 \mathrm{~h}$, watering was carried out ad lib from automatic water troughs. The animals were operated with the imposition of fistulas of the rumen according to V.A. Basov's method. Animals were kept in individual stalls. During the preliminary and reference periods, the prescribed feeds and their residues were properly recorded. During the reference period, average samples of feed, feed residues, feces and urine were collected according to the conventional methodology of carrying out digestibility tests (Tomme, 1969). Physiological studies included digestion trial to determine the digestibility and nutrient intake of feeds using conventional techniques. This involved preliminary equalization period (14 days), followed by the feeding of preparation-containing feed (21 day) and actually reference period (7 days) (Ovsyannikov, 1976).

Feed along with feed residue, duodenal chyme and feces were tested in terms of content of Crude Fat (CF), which was determined by the method of S.V. Rushkovsky; Crude Fiber (CF) -determined according to Henneberg and Shimano method; Crude Ash (CA) determined by combustion in a muffle furnace; calcium and phosphorus -determined by complex-metric method; Free-Nitrogen Extracts (FNE) and Organic Matter (OM) -determined by calculation.

For the characteristics of ruminal digestion, samples of the ruminal contents from animals' fistula were taken $1 \mathrm{~h}$ before and $3 \mathrm{~h}$ after feeding. At that, we determined $\mathrm{pH}$ of ruminal content, biomass of protozoa and bacteria using the differentiated centrifugation method (Tarakanov et al., 1982). In the liquid portion the total amount of Volatile Fatty Acids (VFA) were determined by means of Markham apparatus; ammonium nitrogenby microdiffusion method; and amylase activity of the ruminal fluid -by photometric method.

The blood serum of animals was tested in terms of content of total protein and its fractions, transamination enzymes (ALT and AST), Blood Urea Nitrogen (BUN), creatinine, cholesterol, alkaline phosphatase, bilirubin, triglycerides, glucose, minor constituents and macronutrients. He tests were performed using Chem Well (Awareness Technology) analyzer (USA). Red Blood Cell count (RBC), White Blood Count (WBC), hemoglobin contents and $\mathrm{RBC}$ plasma ratio were determined in whole blood. Digital data were processed by variational-statistical method.

\section{Results}

It is revealed that the palatability of the concentrates were similar in all groups of animals. Introduction of ACS additionally to the sheep's diet contributed to increase of dry matter consumption by 2.0 and $8.4 \%$ in sheep of Romanov breed and hybrid of Romanov breed and argali, respectively. Change in the diet composition by the inclusion of the preparation contributed to the increase in consumption of OM by $7.6 \%$ in animals of all genotypes. Analyzing data of Table 1, we can note that energy nutrition of diets calculated based on digestibility coefficients was different for various groups. The content of Metabolic Energy (ME) in sheep's diet in the control period amounted to 8.4 and 8.9 MJ that is by 0.5 and 1.2 MJ less than that in the animals in the experimental period. Higher digestibility of nutrients in sheep's diets treated with the ACS containing diets allowed also increasing the concentration of energy in the dry matter of the diets.

It is established that the nutrients ratios in the diets of experimental animals were similar, with the exception of organic matter and ash, i.e., the introduction of ACS enriched animal diet with minor constituents and macronutrients. We noted the increase in consumption of crude protein by test sheep that may be due to a larger consumption of dry matter, while increased content of digestible protein in the diets is caused by increased protein digestibility in the gastrointestinal tract due to application of the preparation. Indicators of ruminal digestion are summarized in Table 2 and 3.

The change in $\mathrm{pH}$ of the medium in experimental animals is subject to the following regularity: Neutral and slightly acidic medium before feeding and slightly acidic medium after feeding. This is due to the intensification of fermentation processes and formation of acidic metabolites in the rumen after feed intake. This pattern is observed in animals of all experimental groups.

The total amount of volatile fatty acids and carbohydrates cleavage products in forest mach naturally increased in the ruminal fluid after feeding animals during the control and experimental research periods. After feeding, the concentration of volatile fatty acids in animals in the experimental period was higher than that in control group that can serve an evidence of intensification of hydrolysis of carbohydrates in animals treated with ACS.

A sharp increase in the level of ammonia after feeding was observed in all groups and periods of experiment. In control groups of sheep it was 98 and $164 \%$ (in purebred and hybrid animals, respectively), while in experimental sheep -88 and $145.5 \%$, respectively. At that, in animals treated with ACS, the concentration of ammonia in the ruminal content was lower both before and after feeding. Experimental sheep of Romanov breed showed decrease in ammonia concentration by $1.44 \mathrm{mg} \%$ (14.1\%) before feeding and by $3.76 \mathrm{mg} \%(22.9 \%)$ after feeding compared to the control animals. In hybrid animals, this difference amounted to $1.08 \mathrm{mg} \%(13.7 \%)$ and $4.3 \mathrm{mg} \%$ (22.2\%), respectively. Most likely, this is due to the fact that ACS, as many sorbents, has the ability to bind ammonia. 
Table 1. Composition and nutritional value of diets while carrying out studies

\begin{tabular}{|c|c|c|c|c|c|c|c|c|}
\hline \multirow[b]{3}{*}{ Feed } & \multicolumn{5}{|l|}{ Group } & & & \\
\hline & \multicolumn{2}{|c|}{ Control } & \multicolumn{3}{|c|}{ Experimental } & & & \\
\hline & ROM & ROMARG & ROM & $\mathrm{ROM}$ & & & & \\
\hline Hay, kg & 1.2 & 1.2 & 1.2 & 1.2 & & & & \\
\hline Complete feed, kg & 0.40 & 0.40 & 0.40 & 0.40 & & & & \\
\hline Finesalt, $\mathrm{g}$ & 5.0 & 5.0 & 5.0 & 5.0 & & & & \\
\hline ACS, $g$ & - & - & 3.0 & 3.0 & & & & \\
\hline \multicolumn{9}{|l|}{$\begin{array}{l}\text { Content of the diet (based on } \\
\text { actually consumed feed): }\end{array}$} \\
\hline \multicolumn{9}{|l|}{ 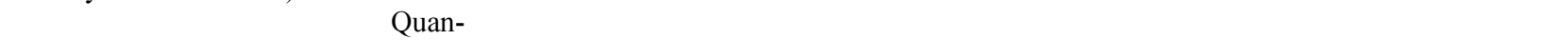 } \\
\hline Tity & $\%$ & Quan- & & & & & & \\
\hline Tity & $\%$ & Quan- & & & & & & \\
\hline Tity & $\%$ & Quan- & & & & & & \\
\hline Tity & $\%$ & & & & & & & \\
\hline Metabolicenergy (ME), MJ & 8.4 & & 9.4 & & 8.9 & & 10.6 & \\
\hline Dry Matter (DM), g & 878.0 & 100.0 & 922.4 & 100.0 & 896.0 & 100.0 & 1000.0 & 100.0 \\
\hline Organicmatter (OM), g & 820.3 & 93.4 & 882.8 & 95.7 & 816.0 & 91.1 & 949.6 & 94.9 \\
\hline Crude Protein (CP), g & 106.5 & 12.1 & 129.0 & 14.0 & 111.0 & 12.4 & 130.4 & 13.0 \\
\hline Digestible Protein (DP), g & 65.5 & & 88.7 & & 74.2 & & 91.7 & \\
\hline Crude fat (CF), g & 22.0 & 2.5 & 20.4 & 2.2 & 24.0 & 2.7 & 24.4 & 2.4 \\
\hline Crude Fiber (CFI), g & 184.7 & 21.0 & 190.0 & 20.6 & 162.6 & 18.1 & 212.3 & 21.2 \\
\hline Free-Nitrogen Extracts (FNE), g & 507.1 & 57.8 & 543.4 & 58.9 & 518.4 & 57.9 & 582.5 & 58.3 \\
\hline Crude Ash (CA), g & 57.7 & 6.6 & 39.6 & 4.3 & 80.0 & 8.9 & 50.4 & 5.0 \\
\hline
\end{tabular}

Table 2. Dynamics of ruminal metabolism indicators

\begin{tabular}{|c|c|c|c|c|}
\hline \multirow[b]{3}{*}{ Group } & \multicolumn{4}{|l|}{ Sampling time } \\
\hline & \multicolumn{2}{|l|}{ ROM } & \multicolumn{2}{|l|}{ ROMARG } \\
\hline & Before feeding & After feeding & Before feeding & After feeding \\
\hline \multicolumn{5}{|l|}{$\mathrm{PH}$ in the ruminal contents } \\
\hline Control & $6.77 \pm 0.02$ & $6.40 \pm 0.09$ & $6.77 \pm 0.08$ & $6.80 \pm 0.03$ \\
\hline Experiment & $6.86 \pm 0.09$ & $6.18 \pm 0.14$ & $6.40 \pm 0.12$ & $6.23 \pm 0.09$ \\
\hline \multicolumn{5}{|l|}{$\begin{array}{l}\text { Volatile Fatty Acids (VFA) in } \\
\text { ruminal liquid (Mmole/100 } \mathrm{mL}^{-1} \text { ) }\end{array}$} \\
\hline Control & $7.91 \pm 0.25$ & $12.0 \pm 0.500$ & $10.13 \pm 0.70$ & $12.30 \pm 0.70$ \\
\hline Experiment & $7.87 \pm 0.43$ & $12.34 \pm 0.64$ & $10.15 \pm 0.60$ & $14.0 \pm 0.500$ \\
\hline Experiment to control ratio, $\%$ & 99.5000000 & 102.8000000 & 100.2000000 & 113.8000000 \\
\hline \multicolumn{5}{|c|}{ Ammonia in ruminal liquid ( $\mathrm{mg} \%$ ) } \\
\hline Control & $10.20 \pm 0.90$ & $20.20 \pm 1.30$ & $8.98 \pm 0.70$ & $23.7 \pm 1.940$ \\
\hline Experiment & $8.76 \pm 0.80$ & $16.44 \pm 1.23 *$ & $7.90 \pm 0.70$ & $19.40 \pm 1.30$ \\
\hline Experiment to control ratio, \% & 85.9000000 & 81.4000000 & 87.9000000 & 81.8000000 \\
\hline \multicolumn{5}{|c|}{ Enzyme activity after feeding $(\mathrm{E} / \mathrm{ml})$} \\
\hline Control & $14.28 \pm 0.60$ & $15.63 \pm 0.15$ & & \\
\hline Experiment & $18.42 \pm 0.15^{*}$ & $18.71 \pm 0.16^{*}$ & & \\
\hline Experiment to control ratio, \% & 129.0000000 & 119.7000000 & & \\
\hline
\end{tabular}

*Note: 0.05

Amylase activity of the ruminal fluid was higher by $19.7-29.0 \%$ in animals treated by ACS, as compared to the control. Data indicating the increase in mass of symbiotic micro rganismsin ruminal contents testify more intense course of microbial processes in forest mach under the influence of ACS (Table).

It can be noted that changes in the composition of diets, when treating animals with preparation, had an impact on the amount of symbiotic microflora in the rumen, bothprotozoa and bacteria. We noted increase in the number of bacteria in the rumen of experimental animals. Before feeding, the difference in Romanov sheep was $7.4 \%$, while in hybrid sheep $-5.2 \%$ compared to the control; after feeding these figures amounted to 12.8 and $7 \%$, respectively. The number of protozoa also increased in the rumen of Romanov sheep before feeding 
by $34.4 \%$, while in the hybrid sheep-by $23.2 \%$; consequently, after feeding-by 2.0 and $25.4 \%$, respectively. The total number of symbiotic microorganisms increased as well. Apparently, during the application of ACS the environment for the growth of protozoa in the rumen of the animals was more favorable than that in the controls. The increase in mass of symbiotic microflora leads to increase in nutrients digestibility as well as better nitrogen utilization by the ruminal microflora. Thus, the introduction of ACS into the diet at a dose of $1 \mathrm{~g} / 10 \mathrm{~kg}$ of live weight of animals contributes to the optimization of fermentation processes in the rumen and, as a consequence, creates in ruminal environment more favorable conditions for development of microflora and improvement of digestibility of nutrients in diets.

Introduction of ACS to the diets composition improved digestion processes in the animals of experimental groups that had a positive effect on the digestion of certain nutrients (Table 4).

It is established that the digestibility coefficients and the total digestible nutrients were higher in animals treated with the preparation formulated into feed regardless the animals genotype. Particularly, we can point to a statistically significant increase in digestibility of CP (by 7.2 abs.\% in Romanov sheep and 3.5 abs.\% in hybrid animals) and CF (by 4.3 and 6.1 abs.\%, respectively). This may be due to increase in biomass of bacteria in the rumen of animals from the experimental groups and the creation of more favorable conditions for their vital activity. We noted statistically significant increase in the amount of digested CP and CFI in animals treated with preparation. Thus, the amount of digested CP in Romanov sheep was by $35.4 \%$ higher than that in controls. In hybrid sheep fed ACS, the amount of digested CP increased by $23.6 \%$, while digested CFI -by $34 \%$ compared to the control animals.

Nitrogenous substances undergo significant metamorphosis in the body of ruminants. The leading role in the metabolism of protein belongs to the rumen of the ruminants (Table 5).
Much higher nitrogen intake with feed was noted in the animals of experimental groups due to higher intake of dry organic matter and protein. The amount of nitrogen released with feces in the experimental groups of sheep was lower. The advantage of using nitrogen along with higher feed gain and nitrogen utilization was identified in the body of sheep treated with ACS, formulated into diets. Nitrogen stored in the body of the control animals amounted to 5.06 and $6.04 \mathrm{~g}$ that is by 2.44 and $3.0 \mathrm{~g}$ less than that in the experimental animals. Nitrogen utilization coefficients in sheep which were fed ACS was by 6.9 and 9.7 abs.\% higher than that of control sheep.

Analysis of biochemical and hematological parameters (Table 6-8) showed that the supplement of the preparation into the diets of sheep did not negatively impact on the indicators of protein, fat, carbohydrate, mineral metabolism and contents of formed elements. All biochemical indicators were within the permissible physiological norms. However, some indicators were subject to fluctuations.

The decline of blood urea nitrogen concentration in animals of the experimental groups correlates by 22.8 and $15.5 \%$ with a decrease in ammonia nitrogen concentration in the rumen. The glucose level was higher by $0.17-0.48 \mathrm{Mmol} \mathrm{L}^{-1}$ that may indicate higher energy supply of animals' body when receiving preparation with a diet. The decrease in the level of bilirubin by $40.8 \%$ and cholesterol by $15.8 \%$ in the blood serum of experimental animals may reflect the improvement of functional activity of the liver and assume antitoxic role of ACS. During the experiment, the activity of alkaline phosphatase in animals of the experimental groups was lower that may indicate the increase of energy supply of the tissue cells in the form of ATF.

Mineral metabolism of experimental animals was characterized by the same content of calcium, phosphorus, magnesium and iron in the blood of experimental and control sheep.

Hematological analysis revealed certain increase in the level of hemoglobin, as well as reduction in the content of leukocytes in the blood of animals fed ACS.

Table 3. Content of microbial mass in ruminal fluid

\begin{tabular}{|c|c|c|c|c|c|c|}
\hline \multirow[b]{3}{*}{ Group } & \multicolumn{6}{|c|}{ In the $100 \mathrm{~mL}^{-1}$ of the ruminal content, $\mathrm{mg}$} \\
\hline & \multicolumn{3}{|c|}{ Before feeding } & \multicolumn{3}{|c|}{ After feeding } \\
\hline & Bacteria & Protozoa & Total & Bacteria & Protozoa & Total \\
\hline \multicolumn{7}{|l|}{ ROM } \\
\hline Control & $389 \pm 11.4$ & $360 \pm 35$ & $749 \pm 45$ & $470 \pm 22$ & $523 \pm 71$ & $993 \pm 84$ \\
\hline $\begin{array}{l}\text { Experiment } \\
\text { ROMARG }\end{array}$ & $418 \pm 25$ & $484 \pm 66$ & $902 \pm 78$ & $530 \pm 25$ & $533 \pm 44$ & $1063 \pm 42$ \\
\hline Control & $519 \pm 32$ & $499 \pm 20$ & $1018 \pm 43$ & $588 \pm 50$ & $552 \pm 35$ & $1140 \pm 70$ \\
\hline Experiment & $546 \pm 67$ & $615 \pm 24^{*}$ & $1161 \pm 28^{*}$ & $634 \pm 14$ & $692 \pm 34$ & $1326 \pm 62$ \\
\hline
\end{tabular}


Nadezhda Vladimirovna Bogolyubova et al. / OnLine Journal of Biological Sciences 2017, 17 (2): 121.127 DOI: 10.3844/ojbsci.2017.121.127

Table 4. Amount and digestibility of nutrients

\begin{tabular}{|c|c|c|c|c|}
\hline \multirow[b]{3}{*}{ Indicator } & \multicolumn{4}{|l|}{ Group } \\
\hline & \multicolumn{2}{|l|}{$\mathrm{ROM}$} & \multicolumn{2}{|l|}{ ROMARG } \\
\hline & Control & Experiment & Control & Experiment \\
\hline \multirow[t]{2}{*}{$\overline{\mathrm{DB}}, \mathrm{g}$ digestibility, $\%$} & $570.9 \pm 24.6$ & $620.8 \pm 28.3$ & $620.8 \pm 35.8$ & $702.8 \pm 29.70$ \\
\hline & $65.0 \pm 1.70$ & $67.3 \pm 2.40$ & $69.3 \pm 1.60$ & $70.3 \pm 0.700$ \\
\hline \multirow[t]{2}{*}{ OM, g digestibility, $\%$} & $548.8 \pm 23.4$ & $612.7 \pm 26.0$ & $594.0 \pm 35.0$ & $685.6 \pm 29.20$ \\
\hline & $66.9 \pm 1.60$ & $69.4 \pm 2.20$ & $72.8 \pm 0.80$ & $72.2 \pm 0.800$ \\
\hline \multirow[t]{2}{*}{$\mathrm{CP}, \mathrm{g}$ digestibility, $\%$} & $65.5 \pm 1.30$ & $88.7 \pm 3.3 *$ & $74.2 \pm 1.40$ & $91.7 \pm 1.5 * 0$ \\
\hline & $61.5 \pm 1.80$ & $68.7 \pm 2.2 *$ & $66.8 \pm 1.60$ & $70.3 \pm 1.100$ \\
\hline \multirow[t]{2}{*}{$\mathrm{CF}, \mathrm{g}$ digestibility, $\%$} & $12.5 \pm 0.70$ & $12.5 \pm 1.10$ & $14.7 \pm 0.50$ & $16.5 \pm 1.200$ \\
\hline & $56.8 \pm 0.70$ & $61.1 \pm 1.90$ & $61.5 \pm 1.90$ & $67.6 \pm 1.3 * 0$ \\
\hline \multirow{2}{*}{ CFI, g digestibility, \% } & $109.7 \pm 5.50$ & $115.0 \pm 6.90$ & $101.8 \pm 5.60$ & $136.5 \pm 8.6 * 0$ \\
\hline & $59.4 \pm 1.90$ & $60.6 \pm 2.50$ & $62.6 \pm 1.10$ & $64.3 \pm 1.400$ \\
\hline \multirow[t]{2}{*}{ FNE, g digestibility, $\%$} & $361.5 \pm 17.5$ & $396.7 \pm 16.7$ & $388.8 \pm 30.1$ & $441.0 \pm 19.90$ \\
\hline & $71.3 \pm 1.70$ & $73.0 \pm 2.20$ & $75.0 \pm 2.60$ & $75.7 \pm 0.800$ \\
\hline
\end{tabular}

Table 5. Utilization of nitrogen from protein

\begin{tabular}{|c|c|c|c|c|}
\hline \multirow[b]{3}{*}{ Indicator } & \multicolumn{4}{|l|}{ Group } \\
\hline & \multicolumn{2}{|l|}{ ROM } & \multicolumn{2}{|l|}{ ROMARG } \\
\hline & Control & Experiment & Control & Experiment \\
\hline In taken with feed, $g$ & $17.4 \pm 0.40$ & $20.8 \pm 0.6^{*}$ & $17.8 \pm 0.40$ & $20.9 \pm 0.4^{*}$ \\
\hline Containedinfaeces, $\mathrm{g}$ & $6.7 \pm 0.40$ & $6.5 \pm 0.5$ & $5.9 \pm 0.40$ & $6.2 \pm 0.3$ \\
\hline Digested in total, $g$ & $10.7 \pm 0.30$ & $14.3 \pm 0.5^{*}$ & $11.9 \pm 0.30$ & $14.7 \pm 0.2^{*}$ \\
\hline Digestibility coefficient, $\%$ & 61.500000 & 68.70000 & 66.800000 & 70.30000 \\
\hline Released with urine, $g$ & $5.6 \pm 0.60$ & $6.8 \pm 0.6$ & $5.86 \pm 0.5$ & $5.6 \pm 0.50$ \\
\hline Stored in the body, $\mathrm{g}$ & $5.06 \pm 0.6$ & $7.5 \pm 1.0$ & $6.04 \pm 0.4$ & $9.12 \pm 0.4$ \\
\hline Utilization coefficient, $\%$ & 29.100000 & 36.00000 & 33.900000 & 43.600000 \\
\hline
\end{tabular}

Table 6. Biochemical indicators of sheep blood

\begin{tabular}{|c|c|c|c|c|}
\hline \multirow[b]{3}{*}{ Indicator } & \multicolumn{4}{|l|}{ Group } \\
\hline & \multicolumn{2}{|l|}{ ROM } & \multicolumn{2}{|l|}{ ROM } \\
\hline & Control & Control & Control & Control \\
\hline Totalprotein, $\mathrm{g} / \mathrm{l}$ & $74.5 \pm 1.50$ & $74.5 \pm 2.40$ & $71.6 \pm 1.8$ & $71.7 \pm 1.77$ \\
\hline Albumins, $g / 1$ & $28.77 \pm 1.3$ & $29.0 \pm 0.70$ & $28.0 \pm 0.5$ & $28.0 \pm 0.70$ \\
\hline Globulins, $\mathrm{g} / \mathrm{l}$ & $45.7 \pm 1.90$ & $45.5 \pm 2.80$ & $43.6 \pm 2.0$ & $43.7 \pm 1.90$ \\
\hline Albumin/Globulin (A/G) & 0.63000 & 0.640000 & 0.64000 & 0.640000 \\
\hline $\mathrm{ALT}, \mathrm{mcM} / \mathrm{l}$ & $17.4 \pm 1.5$ & $17.84 \pm 3.8$ & $18.9 \pm 1.5$ & $19.4 \pm 2.40$ \\
\hline $\mathrm{AST}, \mathrm{mcM} / \mathrm{l}$ & $98.9 \pm 3.6$ & $96.9 \pm 3.30$ & $88.3 \pm 5.6$ & $93.8 \pm 6.50$ \\
\hline $\mathrm{BUN}, \mathrm{mcM} / \mathrm{l}$ & $8.6 \pm 0.8$ & $7.0 \pm 0.40$ & $6.7 \pm 0.3$ & $5.8 \pm 0.40$ \\
\hline Creatinine, $\mathrm{mcM} / 1$ & $63.5 \pm 8.6$ & $58.6 \pm 2.30$ & $64.3 \pm 5.8$ & $60.4 \pm 5.70$ \\
\hline Bilirubin, $\mathrm{mcM} / 1$ & $13.1 \pm 0.7$ & $9.3 \pm 1.1^{*} 0$ & $9.7 \pm 2.4$ & $8.7 \pm 1.50$ \\
\hline Cholesterol, mcM/1 & $2.7 \pm 0.2$ & $2.3 \pm 0.10$ & $2.2 \pm 0.1$ & $1.9 \pm 0.1^{*} 0$ \\
\hline Alkaline phosphatase, ME/l & $743 \pm 1100$ & $548 \pm 81000$ & $546 \pm 6600$ & $505 \pm 490000$ \\
\hline Glucose, $\mathrm{mcM} / \mathrm{l}$ & $4.1 \pm 0.3$ & $4.58 \pm 0.3$ & $4.2 \pm 0.1$ & $4.37 \pm 0.09$ \\
\hline
\end{tabular}

Table 7. Content of mineral substances in blood serum

\begin{tabular}{|c|c|c|c|c|}
\hline \multirow[b]{3}{*}{ Indicator } & \multicolumn{4}{|l|}{ Group } \\
\hline & \multicolumn{2}{|l|}{ ROM } & \multicolumn{2}{|l|}{ ROM } \\
\hline & Control & Control & Control & Control \\
\hline 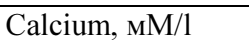 & $2.7 \pm 0.100$ & $2.6 \pm 0.050$ & $2.6 \pm 0.080$ & $2.4 \pm 0.080$ \\
\hline Phosphorus,MM/1 & $1.9 \pm 0.400$ & $1.93 \pm 0.04$ & $2.49 \pm 0.13$ & $2.28 \pm 0.13$ \\
\hline $\mathrm{Ca} / \mathrm{P}$ ratio & 1.4200000 & 1.3400000 & 1.0400000 & 1.0500000 \\
\hline Magnesium, мM/1 & $1.05 \pm 0.09$ & $0.9 \pm 0.070$ & $1.07 \pm 0.06$ & $0.99 \pm 0.07$ \\
\hline Iron,мM/1 & $30.4 \pm 1.400$ & $27.6 \pm 2.400$ & $29.1 \pm 2.200$ & $29.4 \pm 2.000$ \\
\hline
\end{tabular}


Table 8. Hematological indices of sheep blood

\begin{tabular}{|c|c|c|c|c|}
\hline \multirow[b]{3}{*}{ Indices } & \multicolumn{4}{|l|}{ Group } \\
\hline & \multicolumn{2}{|l|}{ ROM } & \multicolumn{2}{|l|}{ ROM } \\
\hline & Group & Group & Group & Group \\
\hline Erythrocytes, $10^{12} / 1$ & $13.8 \pm 0.7$ & $14.9 \pm 0.2$ & $15.8 \pm 0.3$ & $14.5 \pm 1.5$ \\
\hline Leukocytes, $10^{9} / 1$ & $32.6 \pm 3.5$ & $18.3 \pm 1.3^{*}$ & $36.6 \pm 4.1$ & $22.5 \pm 2.5^{*}$ \\
\hline Hemoglobin, g/l & $121.7 \pm 2.1$ & $126.3 \pm 3.5$ & $136.7 \pm 2.7$ & $137.1 \pm 2.3$ \\
\hline Hematocrit, $\%$ & $47.1 \pm 3.4$ & $49.3 \pm 0.3$ & $55.0 \pm 1.7$ & $53.8 \pm 1.5$ \\
\hline
\end{tabular}

The lowest average daily gain in live weight was obtained in animals of control groups and amounted to 159.2 and $175.2 \mathrm{~g}$. When supplemented the diets of Romanov sheep with ACS, this figure was by $11.5 \%$ higher than that in the sheep of control group. The difference in daily gain in live weight of control animals in the hybrid group amounted to $16.0 \%$.

\section{Discussion}

Various sorbents (clay materials, zeolites, verminities, bentonites and various polymeric substances) are widely used to prevent and treat gastrointestinal disorders, as well as neutralize xenobiotics and mycotoxins (Belkin, 2003). In the rumen of ruminants, natural mineral sorbents regulate biochemical processes, the amount of ammonia and ammonium nitrogen, stabilize the medium reaction, increase the content of volatile fatty acids, activate the fermentation of carbohydrates, the biological synthesis of microbial protein and some enzymes (Kuznetsov, 1994). Along with the positive aspects of natural mineral sorbents we should note narrow range of their adsorption efficiency. Besides, along with the my cotoxins they bind also essential substances. The relatively high rates of required mineral sorbents cause a risk of blocking the digestive system elements. Many sorbents are unsafe for humans when working with them and even in contact with the skin (for example, Mycosorb and Microbond made in USA). Many of the known sorbents have selective effect with respect to mycotoxins and are ineffective at low doses of input into the animal diet. The use of activated charcoal for the prevention and treatment of farm animals poisoning by mycotoxins and other harmful substances is of particular interest (Zenkin et al., 2014a; 2014b).

The ACS used in these studies, is a highly dispersed porous material with a developed specific surface area and a unique ability to absorb considerable amounts of substances of different chemical nature. It is produced from eco-friendly charcoal according to special technology and has no impurities. In appearance ACS is a grain of black color. Screening studies revealed the safety of this preparation for animals. Present studies proved the effectiveness of using ACS in sheep treatment that allowed us to formulate the following conclusions.

\section{Conclusion}

The use of activated charcoal as a feed additive in the diets of growing Romanov sheep and their hybrids with argali contributes to the increase in consumption of basic feed ration, increases formation of volatile fatty acids, reduces the concentration of ammonia in ruminal contents as well as increases the amylase activity.

The application of the preparation contributed to raising the level of microbial mass formation in the ruminal content by $70-186 \mathrm{mg} / 100 \mathrm{ml}$, increased the obvious digestibility of nutritive matter, such as dry substances -by 1.0-2.3 abs.\%, crude protein -by 3.5-7.2 abs. $\%$, crude fat -by 4.3-6.1 abs.\%, crude fiber $-1.2-1.7$ abs. $\%$ and nitrogen-free extractives - by $0.7-1.7$ abs.\%.

The supplement of the preparation into the diets of sheep has not had a negative effect on the indices of protein, fat, carbohydrate and mineral metabolism, as well as content of formed elements. All biochemical indicators as well as content of mineral substances were within permissible physiological norms.

Nitrogen utilization coefficients when feeding animals with charcoal sorbent was by 6.9 and 9.7 abs.\% higher than those of control animals. Adding in the diets of activated charcoal contributed to increase of average daily gain of sheep by $11.5-16.0 \%$.

To optimize digestion, improve the digestibility and utilization of nutrients contained in feed rations of ruminants, as well as growth of their productivity, we recommend using activated charcoal as a feed additive in a dose of $1 \mathrm{~g}$ per $10 \mathrm{~kg}$ of live weight of animals.

\section{Acknowledgement}

We would like to thank all the persons who helped us to carry out this work in its different stages.

\section{Author's Contributions}

Nadezhda Vladimirovna Bogolyubova: Designed the study, assisted sample collection, data analysis and manuscript preparation. 
Vasily Pavlovich Korotky: Participated in manuscript preparation and results discussion.

Alexander Sergeyevich Zenkin: Participated in manuscript preparation and results discussion.

Viktor Anatolyevich Ryzhov: Designed the study, assisted sample collection, data analysis and manuscript preparation.

Nikolai Petrovich Buryakov; Designed the study, assisted sample collection, data analysis and manuscript preparation.

\section{Ethics}

This article is original and contains unpublished material. The corresponding author confirms that no ethical issues involved.

\section{References}

Aliyev, A.A., 1997. Metabolism in Ruminants. 1st Edn., Engineering Center Inzhener, Moscow, pp: 420.

Aliyev, A.A., 2001. Relationship of the acetate and choline metabolism in the animals and poultry organism. Urgent Problems of Biology in Animal Agreeculture. Borovsk, pp: 205-214.

Belkin, B.L., 2003. Influence of Hotynetsky natural zeolites on physiological functions, immunological parameters and productivity of animals and birds. Proceedings of the International Scientific-Practical Conference "Urgent Problems of Veterinary Medicine, Ulyanovsk State Agricultural Academy, Ulyanovsk.

Ernst, L.K. and N.A. Zinovieva, 2008. Biotechnology in Animal Production. 1st Edn., Moscow, pp: 510.

Kuznetsov, S.G., 1994. Use of Natural Zeolites in Animal Production. 1st Edn., Overview of NIITET, Agroprom Moscow.
Ovsyannikov, A.I., 1976. Fundamentals of Experimental Work in Animal Production. 1st Edn., Kolos, Moscow, pp: 303.

Romanov, V.N., N.V. Bogolyubova, M.G. Chabaev, R.V. Nekrasov and V.A. Devyatkin et al., 2015. Optimization of Digestive, Metabolic Processes and Functions of the Liver in Dairy Cattle. 1st Edn., Monograph, Dubrovitsy, pp: 152.

Tremasova, A.M., 2014. Pharmaco-toxicological rationale for the use in veterinary of natural mineral of shungite and shungite-based preparations: nanosorbents of polisorbin and polisorb. PhD Thesis, Kazan.

Sinechshokov, A.D. and Z.I. Sheremet, 1953. Methodology of Comprehensive Study of the Physiological Nutrition Process. Nutrition Physiology of Farm Animals. 1st Edn., Selkhozgiz, Moscow.

Tomme, M.F., 1969. Technique to Determine the Digestibility of Feeds and Rations. 1st Edn., Kolos, Moscow, pp: 39.

Tarakanov, B.V., T.A. Nikolicheva and T.A. Shavyrina, 1982. Modification of the separation of microbial fractions from the ruminal content and the duodenal chyme. Bulletin of all-russian scientific research institute of physiology. Biochem. Nutrit. Anim., Borovsk, 2: 72-75.

Zenkin, A.S., A.I. Leytkin, A.Y. Chinyaeva, V.P. Korotky and V.A. Ryzhov et al., 2014a. Active coal feed additive: An effective means of preventing chronic my cotoxicosis and increasing egg production by laying hens. Adv. Biol., 8: 197-200.

Zenkin, A.S., A.I. Leytkin, A.Y. Chinyaeva, O.N. Lukyanov and V.P. Korotky et al., 2014 b. Scientific and experimental substantiation of application of active coal feed additive at breeding broiler chickens of the Cobb-500 cross. Adv. Biol., 8: 372-376. 